\title{
CUANDO LA JUSTICIA NOS ALCANCE: LA IGLESIA DE AGUASCALIENTES ANTE LA DESIGUALDAD SOCIAL
}

YOLANDA PADILLA RANGEL

Departamento de Historia/UAA

José Antonio Gutiérrez, La labor social de la Iglesia en Aguascalientes, Aguascalientes, Instituto Cultural de Aguascalientes, 1997, 447 pp.

M. razones. La primera es que el autor es un apreciado colega y compañero de trabajo. Quiero mencionar aquí la notable vocación de historiador que yo observo en José Antonio, así como su fuerte inclinación a la concentración, al silencio, a la meditación, al trabajo minucioso, ya que es en esta actitud de trabajo en que día tras día lo veo en su cubículo del Departamento de Historia de la Universidad. La segunda razón es que el tema que toca en su libro me interesa, tanto académica como personalmente: la labor social de la Iglesia Católica en Aguascalientes, es decir, la actividad que la Iglesia Católica, como institución, ha emprendido frente a los problemas de la sociedad local. Este tema cobra relevancia si consideramos que la Iglesia es una de las instituciones sociales más importantes de la sociedad mexicana. Este libro cubre también una gran parte de la historia de la Iglesia en Aguascalientes y, además, es más o menos novedoso en su género, ya que las historias de la Iglesia en México generalmente se hacían, hasta hace poco, con una perspectiva nacional, con fuentes secundarias y con una posición apologética de ella. Lo que hace José Antonio es una aproximación regional a la historia de la Iglesia, con fuentes primarias, y desde una posición que intenta ser más académica que estrictamente institucional.

\section{EL PROBLEMA DE FONDO}

La labor social de la Iglesia diocesana trata de ser coherente con el pensamiento de 
la institución respecto a los problemas económicos y sociales, pensamiento también llamado doctrina social católica. Este pensamiento de la jerarquía católica sobre la cuestión social está comprendido en varios documentos oficiales, encíclicas y discursos del Papa principalmente, en los que se define la posición de la Iglesia respecto a diferentes problemas sociales por los que ha transitado la humanidad desde el siglo pasado.

Es por esto que el autor hace, en el primer capítulo, una rápida revisión de los documentos de la Iglesia que se refieren a la cuestión social, desde la encíclica Rerum Novarum que el Papa León XIII expidió en 1891, hasta la Centesimus annus, que el Papa Juan Pablo II elaboró para recordar los cien años de la Rerum Novarum. Como sabemos, la encíclica Rerum Novarum sentó las bases del pensamiento social católico en torno a la cuestión social, al tratar de adaptar los principios evangélicos a las "cosas nuevas" o nuevos problemas de la realidad social del siglo XIX, es decir, al surgimiento de grandes masas de obreros pobres y desprotegidos que la revolución industrial y el desarrollo del capitalismo habían engendrado.

A partir de esa encíclica, el pensamiento social de la Iglesia ha evolucionado, sin transformar sus premisas centrales, que giran en torno a la dignidad del trabajador y su trabajo, a los deberes de los empresarios y a las responsabilidades que tienen el Estado, la sociedad civil y la Iglesia ante los problemas relacionados con el mundo del trabajo. El problema social que está detrás de todo, es el que se refiere a la injusticia social y el pensamiento social católico representa la respuesta teórica que la Iglesia Católica le ha dado, así como la labor social representa las acciones históricas que la Iglesia ha emprendido para enfrentarlo.

El libro de José Antonio es importante porque nos narra precisamente la respuesta concreta que la diócesis de Aguascalientes ha dado ante un problema social que nos atañe a todos los que formamos parte de la sociedad de Aguascalientes, seamos o no católicos: el de la injusticia social.

\section{LAS APORTACIONES}

El libro es muy rico en cuanto a material histórico se refiere. Estamos ante un texto con abundante información, ordenada en torno a cuatro temas fundamentales que el autor seleccionó: 1. Labor religiosa; 2. Labor educativa; 3. Labor social; y 4. Hospitales y Orfanatos. El autor analiza estos temas a lo largo de cuatro capítulos que corresponden a periodos históricos diferentes: el que se refiere a la época en que aún no existía la diócesis como tal, sino 
como parroquia; luego viene el capítulo que comprende de la fundación de la diócesis, en 1891, hasta 1930, año en que, una vez terminado el movimiento cristero, comienza para la Iglesia un periodo de recomposición y reconciliación con el Estado; posteriormente se encuentra el capítulo que va de la firma de los "arreglos" que dieron fin al movimiento cristero, hasta la realización del Concilio Vaticano II, acontecimiento de amplias dimensiones y consecuencias para el mundo católico; y finalmente está el capítulo que va de la clausura del Concilio hasta 1994, año en que el autor decide terminár su relato, sin que se trate de una fecha significativa para la vida eclesial. Esta periodización tiene una lógica completamente institucional, ya que señala hitos importantes en la historia de la Iglesia Católica a nivel local, nacional e internacional.

Todos los capítulos del libro son ricos en información histórica original. El de "labor religiosa" documenta algunos rasgos de la vida piadosa de los habitantes de la diócesis, a través sobre todo de la existencia de varias asociaciones que se han dedicado a fomentar el culto y la devoción a algún personaje divino o humano, pero al que se le ubica ya en la corte celestial. Estas asociaciones son importantes por ser pequeños grupos sociales que han actuado como organizaciones intermedias en- tre la jerarquía eclesiástica y las bases católicas. Son grupos que han tenido objetivos y características diferentes, tanto en su "objeto" de culto como en sus prácticas y en su inserción social; es decir, han tenido su especificidad religiosa y social. Mediante estas asociaciones, muchos católicos se han insertado en la institución y han tratado de poner en práctica su fe, al tiempo que la asociación los ha dotado de una identidad religiosa y social. Es decir, las prácticas de culto y el afán por imitar a algún personaje celestial han asemejado entre sí a los miembros de una asociación. En este sentido, la fe religiosa y las prácticas que ésta conlleva han reafirmado lazos entre los practicantes y su pertenencia y similitud de prácticas los ha dotado de identidad religiosa y también social, ya que la actividad religiosa ha trascendido socialmente, sobre todo en forma de solidaridad y ayuda al prójimo más desfavorecido.

Los nombres de las asociaciones no mencionadas no están huecos, ya que se trata de agrupaciones que han contado con nutridas participaciones en diferentes momentos de la historia de Aguascalientes. Es una presencia que se ha podido observar silenciosa pero constante en la sociedad local. A través de la lectura del libro de José Antonio, uno puede observar la permanencia histórica, hasta hace po- 
co o incluso hasta la actualidad, de varias de estas asociaciones, por ejemplo la Adoración Nocturna, la Vela Perpetua, la Asociación al Culto Perpetuo al Señor San José, etc., así como el surgimiento y extinción de otras que respondían a la sensibilidad religiosa del momento.

También encontramos en este libro la bien documentada labor de la Acción Católica, que surgió en 1930, con sus ramas de hombres adultos (Unión de Católicos Mexicanos); de mujeres adultas (Unión Femenina Católica Mexicana), mujeres jóvenes (Unión Femenina Católica Mexicana) y hombres jóvenes (Asociación Católica de Jóvenes Mexicanos). Esta asociación ha permanecido hasta la actualidad, si bien desde los años sesenta comenzó a declinar, no sólo a nivel local sino también nacional e internacional. Yo preguntaría al autor si la labor de esta asociación no quedaría mejor en otro rubro que no fuera el estrictamente religioso, ya que desplegó también, sobre todo durante los años 40's y 50 's, una gran actividad cívica, moralizadora de las costumbres y hasta de tipo político, pues muchos de sus participantes nutrieron las filas del PAN, a pesar de que se desarrolló como una asociación aparentemente "despolitizada" y en un tipo de acción de corte muy convencional en lo que a subordinación del seglar a la jerarquía se refiere.
En este rubro de labor religiosa podemos encontrar, bien documentada también, la amplia labor de catequesis que, durante todas las épocas analizadas por el autor, ha desarrollado la Iglesia local a través de organizaciones que han cambiado su nombre, pero no su función, y que constantemente han organizado campañas de instrucción religiosa, tanto en el medio urbano como en el rural. El autor también documenta someramente la organización de las actividades religiosas que han emprendido diversos obispos de la diócesis, tales como fiestas, peregrinaciones, coronaciones, consagraciones y todas las que se refieren a las diversas manifestaciones del culto y la administración de sacramentos. Destacan también en el libro las notas respecto a los sínodos diocesanos.

Bajo el rubro de "Hospitales y Orfanatos", José Antonio Gutiérrez relata, por ejemplo, la labor de las Conferencias de San Vicente de Paul, que desde su fundación en la diócesis han proporcionado asistencia médica a los necesitados, así como alimentos, ropa y otros auxilios. Destaca su atención a diversos asilos de ancianos e indigentes. En este rubro podemos encontrar también la atención que la Iglesia ha dado históricamente a la población necesitada de salud en hospitales como el de San Juan de Dios, que en vísperas de la revolución 
sostenía una escuela primaria y tres asilos de indigentes. Encontramos a las Religiosas Siervas de María atendiendo el Hospital Hidalgo hasta antes de su expulsión en 1926, a las Conferencias de San Juan de Dios atendiendo el Hospital del Sagrado Corazón de Jesús. También podemos observar el origen del Orfanatorio Casimira Arteaga en 1908, la existencia del Hospital San José en la Revolución y otros hospitales atendidos por las Religiosas Mínimas. Así encontramos también el origen y desarrollo del Asilo de Nuestra Señora de Guadalupe, el de la Casa de Regeneración, el de la Ciudad de los Niños, del Oratorio Festivo San Francisco y otros asilos y orfanatos. Encontramos también información sobre otras organizaciones de vida efímera en la diócesis y el surgimiento de Caritas diocesana: la instancia de asistencia social eclesial más importante actualmente, que trata ahora de modernizar su acción asistencial.

En el rubro de Educación el autor nos muestra la gran preocupación educativa de la Iglesia Católica local a través de la fundación y sostenimiento de establecimientos educativos confesionales, a pesar de los impedimentos legales existentes. Podemos ver en el libro que, desde el siglo pasado, los obispos han podido informar al Vaticano de la gran influencia que han podido desarrollar en las escuelas par- ticulares e incluso, en algunos momentos, en las públicas.

Puede destacarse aquí la actividad histórica de la Compañía de María, que fue la primera institución religiosa que fundó colegios para niñas en Aguascalientes y que actualmente atienden el Colegio Guadalupe Victoria; las Religiosas Hijas de la Purísima Virgen María, que atienden el Colegio de la Paz; y, a diferencia de estas religiosas, podemos encontrar a las Maestras Católicas, que atienden varias escuelas para niños pobres. Está también la congregación religiosa Marista, que atiende un colegio que lleva su nombre, etc. Hay que recordar que, a lo largo del siglo y a pesar del anticlericalismo de los gobiernos revolucionarios, la Iglesia pudo atender numerosas escuelas católicas que tuvieron que desempeñarse, en algunos momentos, clandestinamente. Así también, recordar que durante la época cardenista, la Iglesia y los padres de familia instrumentaron una fuerte campaña de resistencia a la educación socialista, que propició que las escuelas públicas se vieran casi totalmente desairadas.

El libro nos permite observar la manera en que la Iglesia Católica ha influido en la organización de los padres de familia y, a través sobre todo de las órdenes religiosas, ha incidido en la fundación de muchas escuelas religiosas particulares, que 
han encontrado su apogeo en la segunda mitad del presente siglo.

\section{LABOR SOCIAL DE LA IGLESIA}

Los antecedentes de la labor social en la diócesis los ubica el autor en 1865, año en que se publicó en Guadalajara el Libro de los Pobres, del francés I. Belouino, que invitaba a reflexionar sobre la dignidad del trabajo, los derechos de los trabajadores y sus posibilidades de asociación. Este libro, al parecer, pudo ser leído por los sacerdotes que luego se incorporaron a la diócesis. Luego vino la publicación de la encíclica Rèrum Novarum, que inspiró a varios católicos locales que dieron origen al movimiento católico social desde fines del porfiriato. El catolicismo social se tradujo en la organización de sindicatos, como el Círculo de Obreros Santa María de Guadalupe; en la organización de programas de formación en el pensamiento social católico; en la organización de cooperativas, cajas de ahorro y en iniciativas de auxilio mutuo entre los trabajadores.

Hay que recordar que la primera época de auge del catolicismo social fue entre 1910 y 1914, cuando se llegó a formar el Partido Católico Nacional, que ganó algunas diputaciones a nivel local. En esta época destaca la actividad del sacerdote Juan Navarrete, quien impulsó fuertemen- te a la Sociedad de Obreros Católicos Guadalupanos y fundó el Círculo Obrero Católico, que tenía el propósito de "explotar moderadamente toda clase de juegos y distracciones honestas y permitidas por la moral". El padre Navarrete impulsó también la Alianza de los Católicos Sociales de Aguascalientes en la época de los embates revolucionarios contra la Iglesia y, en 1919, tuvo que salir exiliado de la diócesis.

Un segundo auge del catolicismo social fue entre 1920 y 1924. En esta ocasión, inspirados en la Rerum Novarum, los católicos fundaron nuevos sindicatos, sociedades de temperancia, periódicos, escuelas, cajas de ahorro, cooperativas y mutualidades. Así surgió la Sociedad Mutualista de Obreros Guadalupanos, que perdió fuerza con el movimiento cristero, luego del cual toda la actividad social eclesial se vio absorbida por la Acción Católica, que desarrolló una actividad totalmente despolitizada, por lo que muchos sindicatos católicos perdieron fuerza casi hasta morir, aunque se reactivaron en 1939, mediante la organización de comités antialcohólicos y, posteriormente, en 1955, con la fundación del Centro Social Navarrete, que reagrupó a los obreros guadalupanos, las cajas de ahorro y otras organizaciones católicas que se encontraban dispersas.

Según nos cuenta el autor, del Concilio Vaticano II hasta la década de los años 
setenta, la acción social se encaminó hacia un desarrollo integral. En el caso de Aguascalientes, el autor documenta que, en los años sesenta, muchos obreros católicos de la localidad participaron en la Asociación Nacional Guadalupana de Trabajadores Mexicanos. También nos relata que, en septiembre de 1969, se formaron la Confederación Diocesana de Cajas Populares y la Unión Regional de Cooperativas de Aguascalientes y, en 1967, el movimiento Empleadas Domésticas y el Centro Social Cristo Obrero. Posteriormente surgió el Centro Recreativo Felipe Morones. En los años setenta surgió el Círculo San Luis Gonzaga para ofrecer a los trabajadores formación moral, religiosa, socioeconómica, cultural y deportiva.

El autor observa que a partir de los años setenta la acción social se redefinió como evangelización liberadora, lo cual quería decir que la acción social católica debía estar presente en las organizaciones sociales, económicas, políticas y culturales. En los años ochenta se fundó la Escuela Diocesana de Doctrina Social, que organizó un seminario sobre la encíclica Laborem Exercens, en colaboración con el Centro Empresarial de Aguascalientes. El Centro Social Navarrete continuó su actividad formativa para los obreros, mientras que la Unión Regional de Cooperativas de Aguascalientes logró conjuntar 8 cajas de ahorros y la
Asociación de Trabajadores Guadalupanos logró aglutinar 617 socios. A pesar de la aparente fuerza numérica de esta asociación, el autor, apoyado en un estudio patrocinado por la Iglesia, en el cual observó que la Asociación ofrecía poca colaboración en la pastoral social y que sus actividades se reducían a asistir a actos religiosos.

\section{EṔĺogo}

La lectura del libro de José Antonio me suscitó muchas preguntas en torno a la puesta en práctica del pensamiento social católico en está diócesis. Las múltiples acciones que en ella se enmarcan, se han denominado históricamente "caridad", "beneficencia" y últimamente "asistencia social". Pero todo ello nos indica que la doctrina social, de una u otra manera, ha podido ponerse en práctica. Tal vez no nos corresponde ahora enjuiciarla, pero sí cuestionarnos sobre su validez e impacto a nivel social. La labor asistencial de la Iglesia ha sido oportuna y eficaz, pero siempre vertical. ¿̨Se ha dado de comer pero no se ha enseñado a pescar? Tal vez hace falta calar a fondo en el concepto de subsidiariedad, que valida la ayuda compensatoria sólo mientras que el que la recibe es capaz de valerse por sí mismo. Tal vez hace falta salir de la acción meramente religiosa y asistencial para enmarcar toda esta 
actividad eclesial en un proyecto social más amplio aún, que contemple articuladamente las dimensiones económica, política, social y cultural, y que realmente combata la injusticia social y no sólo alivie un poco la pobreza.

Me pregunto también sobre el papel que han desempeñado los laicos en todo esto, ya que el Papa en Puebla afirmó que no había que considerar más al laico como un simple "ejecutor" de la política social de la Iglesia, sino como sujeto de pensamiento social y activo colaborador de los sacerdotes. En el documento Apostolicam Actuositatem señaló que los laicos deben ser capaces de aplicar la doctrina social católica en casos concretos y en Gaudium et Spes, mencionó el respeto que se debe al seglar, a su "libertad de investigación, de pensamiento y de hacer, conocer humilde y valerosamente su manera de ver en los campos que son de su competencia".

Este libro me suscitó también la reflexión en torno a la vigencia del pensamiento social católico de fines del siglo pasado. Por ejemplo, las cajas de ahorro que surgieron "con el objeto de formar pequeños capitales y librar a los socios de la usura", ¿no son tan pertinentes ahora como entonces? Lo mismo podría decirse de las cooperativas y otras formas de ayuda mutua entre los trabajadores.
Con todos los méritos que tiene este libro de José Antonio Gutiérrez, no puedo dejar de mencionar algunas fallas, en realidad peccata minuta de los que ninguna obra académica está libre. Creo que la redacción podría ser más clara y directa y que la forma de hacer las citas textuales debería ser más clara también. Por otra parte, tal vez habría que mejorar la siempre difícil articulación entre los acontecimientos locales con los nacionales e internacionales, así como privilegiar la explicación histórica sobre la simple recopilación de datos. Por último, creo que el historiador debe suspender sus juicios de valor, para no empañar la sustancia histórica del relato ni dificultar la comprensión histórica del mismo. $\mathrm{Y}$ aunque cierta forma de parcialidad no puede evitarse por completo, si creo que el historiador debe esforzarse en buscar, si no la neutralidad, si la objetividad y la construcción de la verdad histórica. Estamos ante el caso de un historiador católico que asume como suya la perspectiva de la jerarquía, cuando creo que no es pecado -por usar este término- distanciarse de ella y asumir la propia. El principal inconveniente de asumir la perspectiva jerárquica es que se produce una visión demasiado institucional, podríamos decir oficial de los acontecimientos históricos, que en ocasiones puede llevar a distor- 
siones de la realidad y a omitir otras voces de otros actores y constructores de la historia. Puede darse el caso de que la narración contradiga la verdad histórica. Por ejemplo, noté que, en cierta forma, se evita hablar del conflicto interno que vivió la Iglesia en Aguascalientes en los años setenta, el cual tuvo una innegable dimensión social. Ante esa omisión le recuerdo al autor que como historiador tiene un compromiso con la verdad y que como católico debe tener presente la prudente amo- nestación de Pablo a los tesalonicenses (V:21): "examínenlo todo y quédense con lo bueno".

A pesar de estas fallas, el libro de José Antonio Gutiérrez es una importante aportación al conocimiento de la historia de la Iglesia en Aguascalientes. Su estudio, sin duda, es de suma importancia, entre otras razones porque se trata de una institución que ha estado presente en muchos acontecimientos de la vida social, cultural, política y hasta económica de nuestro estado. 중 